\title{
Benefits of cross-border citizen energy communities at distribution system level
}

\author{
Andreas Stroink $^{\mathrm{a}, *}$, Lea Diestelmeier ${ }^{\mathrm{b}}$, Johann L. Hurink ${ }^{\mathrm{c}}$, Tim Wawer ${ }^{\mathrm{a}}$ \\ ${ }^{a}$ Faculty of Management, Culture and Technology, University of Applied Sciences Osnabrueck, Kaiserstraße 10C, 49809, Lingen Ems, Germany \\ ${ }^{\mathrm{b}}$ Department of European and Economic Law and Groningen Centre of Energy Law and Sustainability, University of Groningen, Oude Kijk in 't Jatstraat 26, 9712EK, \\ Groningen, the Netherlands \\ ${ }^{\mathrm{c}}$ Department of Computer Science, Mathematics and Electrical Engineering, University of Twente, Drienerlolaan 5, 7522NB, Enschede, the Netherlands
}

\section{A R T I C L E I N F O}

\section{Keywords:}

Citizen energy community

Cross-border

EU energy law

System cost

Energy system modelling

\begin{abstract}
A B S T R A C T
One challenge of the EU energy transition is the integration of renewable electricity generation in the distribution system. EU energy law proposes a possible solution by introducing "citizen energy communities" (Directive 2019/944/EU) which may be open for "cross-border participation". This article proposes an innovative way of implementing such cross-border communities by linking distribution systems via a "switchable element", a generation, storage, or consumption asset with a connection to each country. An optimization model has been developed to calculate the system cost savings of such a connection. Linking regions with complementary characteristics regarding electricity generation and demand via a switchable element leads to more efficient system utilization. Findings are relevant for the transposition of "citizen energy communities" in national laws.
\end{abstract}

\section{Introduction}

Raising the share of renewable energy sources (RES) is at the core of the European Union's (EU) energy policy. The EU Directive on the promotion of RES prescribes that at least $32 \%$ of the gross final energy consumption in the EU should be generated on the basis of RES until 2030 (art. 3(1) Directive 2018/2001/EU). Most likely, this share will even be increased to $38-40 \%$ as suggested by the EU Commission in July 2021 in the context of the European Green Deal [1]. Achieving this aim comes with serious challenges. One of them being the integration of distributed electricity generation [2], i.e. production from RES which is connected to the distribution grid, in the electricity system [3,4]. Distribution system operators (DSOs) are facing operational constraints, i.e. congestion, and urgently need to upgrade their networks and the operation by reinforcing grid infrastructure but also by implementing flexibility technologies, for example storage and demand response [5-7]. Growing electrification of the heat and the mobility sector add to the complexity as electricity consumption is expected to rise causing more pressure on the available grid capacity [8]. In this context, this article investigates the EU legal option of linking distribution systems across national borders via locally organized energy communities and quantifies the economic benefits in terms of system cost savings. While the topic of interconnecting electricity systems across borders has widely been investigated, existing research focuses almost exclusively on the transmission system level [9]. It is established that transmission grid expansion and market coupling in Europe have the potential to increase the overall welfare and generation adequacy [10] and that (transmission) grid extensions are essential for a cost-efficient integration of a high share of RES [11,12]. This focus can also be explained historically, as cross-border grid interconnections at transmission system level were designed as additional backup capacities for the national power systems to secure a stable and reliable electricity grid operation [13]. Correspondingly, EU energy law manifested that interconnectors, i.e. the infrastructural link of electricity systems between EU Member States (MS), are exclusively linking the transmission systems of MS and are subject to strict regulation organizing access and usage for the sake of an EU-wide competitive market [14].

In addition to the interconnection of electricity systems at transmission system level, which is a result of formal EU integration, the latest EU directive, establishing common rules for the internal electricity market 2019 (Directive 2019/944/EU) [15], creates the option for civic cooperation in the field of energy at distribution system level by legally establishing a new actor, namely "citizen energy communities" (CEC). CEC may be established by a variety of actors, including public and

\footnotetext{
* Corresponding author.

E-mail address: a.stroink@hs-osnabrueck.de (A. Stroink).
} 
private entities and natural persons and may carry out a variety of activities in the energy supply chain, from production, to distribution, and supply, possibly even across national borders. One distinctive characteristic of CEC is that they need to provide "environmental, economic, or social community benefits for its members/shareholders or the area where it operates" (article 2(11) Directive 2019/944/EU) [16]. Existing research on CEC mainly focuses on facilitating or hindering aspects in law and policy for CECs to flourish [17,18], but the aspect of cross-border CEC is not considered yet.

Linking distribution systems across borders may also facilitate cooperation between EU MS for the energy transition on a local level, especially in border regions. Border regions are typically less developed in economic and infrastructural terms. Partly, this stems from natural borders, i.e. rivers, lakes, or mountains, but to a larger extent this is a result of historical, political and administrative divisions causing mutual distrust between countries and subsequent unwillingness to cooperate [19]. While plenty of obstacles have been removed in the course of EU integration and in particular by the "four freedoms", i.e. free movement of persons, goods, services, and capital, negative effects of borders remain and border regions are still considered to be peripheral and less developed [20]. Alleviating the negative effects of borders, the EU aims at fostering cross-border cooperation (CBC) [21]. Hereby CBC needs to be distinguished from formal European integration, which is a political process between EU MS, as it is a voluntary process which can be broadly characterized as "any type of concerted action between public and/or private institutions of the border regions of two (or more) states, driven by geographical, economic, cultural/identity, political/leadership factors, with the objective of reinforcing the (good) neighbourhood relations, solving common problems or managing jointly resources between communities through any cooperation mechanisms available" [22]. Currently, CBC at local level in the field of energy is in the best case limited or on pilot project scale, but usually absent [23]. The unique focus of this article lies at the intersection of the aforementioned topics. Research on interconnection includes the cross-border aspect, but it does not consider the distribution system level. Research on CEC is focused on the distribution system level, but it does not address the cross-border aspect yet, but research on CBC lacks the link with the energy sector at local level. This article thus investigates this gap, i.e. it focuses on $\mathrm{CBC}$ at distribution system level in the form of energy communities from an economic and EU legal perspective.

In particular, this article proposes a novel solution to facilitate the linkage of distribution systems across borders, namely by implementing "switchable elements" which allow connecting distributed generation (e.g. a wind park or a solar field) or flexibility technologies (e.g. an flexible consumer or storage) to both of the two bordering MS without interconnecting the distribution systems at any point in time. For example, a wind park located close to a national border may have two connections; one to the distribution grid of MS A and the other one to MS B. To guarantee that no interconnection between the systems occurs, it has to be guaranteed that only one of the two connections can be used at a time. Thereby, next to the technical infrastructure, this also requires increased coordination between the involved DSOs. Currently, DSOs are mainly "forwarding" electricity to the final consumers. In an electricity system with increasing amounts of decentralised RES connected to the distribution grid, DSOs have to take a more "active" approach to system operation for example by making use of flexibility sources. The EU legal framework sets requirements in that direction by obliging MS to develop regulation which incentives DSOs to procure flexibility for system operation another in order to improve efficiencies in the operation and development of the distribution system [art. 32, in 15]. Potentially, and as developed in this article, flexibility could also be shared between two distribution systems and thereby be used more efficiently.

This article investigates the options of linking distribution systems via a "switch" across national borders for the purpose of integrating distributed generation from RES and flexibility technologies from a legal and an economic perspective. The central question motivating this research is thus twofold: What are legal options of CEC to connect distribution systems across borders in the EU? And: What are the economic benefits in terms of system cost savings of connecting distribution systems with a switchable element across national borders in the EU? The chosen interdisciplinary approach allows an informed analysis including the limitations and leeway under the current EU legal framework on the electricity sector and the quantification of the benefits of linking distribution systems across borders with a "switch" in terms of system cost savings. This analysis is further enriched by a case study of an EU project exploring new concepts for cross-border energy systems functioning on medium and low voltage levels between the Netherlands and Germany.

This article includes the following sections: after this introduction Section 2 analyses the relevant EU legal framework focusing on CEC. Section 3 briefly outlines technical options on how to implement infrastructural links on the distribution system level. Section 4 quantifies the economic benefits of linking distribution systems across national borders with a "switch" and presents the case study SEREH. Section 5 discusses the results concerning the effect of the switchable element on system costs for the connected regions. Section 6 concludes on the research question and formulates policy recommendations whether and how linking distribution systems across national borders can become a part of the solution to integrate distributed RES and flexibility technologies efficiently and enhance $\mathrm{CBC}$ and foster border regions in the EU.

\section{EU energy law: complementing interconnection with cross- border community benefits?}

Historically, interconnections of electricity systems in Europe were seen as backup capacity for ensuring security of supply. The purpose of interconnections was extended with the aim to establish an internal energy market (IEM) in the EU as interconnection of electricity systems of EU MS facilitates the physical exchange of electricity which is a necessary precondition for cross-border trade. Interconnectors, the infrastructure linking the transmission systems of MS, are defined by Regulation (EU) 2019/943, art. 2(1) as “[...] transmission line which crosses or spans a border between Member States and which connects the national transmission systems of the Member States" [24]. The definition explicitly establishes interconnectors at the transmission system level. As this definition is enshrined in a Regulation, it becomes directly national law (art. 288 Treaty on the Functioning of the EU). There is thus no leniency for the MS to define interconnectors in their national legal frameworks. This prescriptive legal approach can be explained by the fact that interconnectors are a prerequisite for cross-border trade, and thus subject to one of the core EU objectives, i.e. freedom of movement of goods. It is estimated that the further integration of markets via interconnection brings significant economic benefits [25]. To reap those economic benefits, EU energy law establishes special rules for accessing and using interconnection capacity. The main objective is to provide a transparent and cost-reflective tariffication system. In addition, a complex set of specific regulations on interoperability, congestion management, and capacity allocation applies [26]. Despite this dedicated rule set for the use of interconnection capacity, the Agency for Cooperation of European Energy Regulators (ACER) still annually reports that the efficient use of interconnectors for all markets (i.e. day-ahead, intraday and balancing) needs to be improved (see annual market monitoring reports on wholesale electricity markets, latest version [27]).

The fact that the transmission system level is inherent to the definition of interconnectors can be explained by the traditional "top-down" setting of the electricity sector, where large centralised production, mostly on the basis of fossil fuel energy sources, is connected to highvoltage transmission systems transporting large amounts of electricity via long distances closer to the locations of final consumption. However, with the technical sophistication of small-scale production installations running on RES and financial support schemes for the generation of energy from renewable sources, the traditional energy sector setting is 
changing and complemented by a "bottom-up" setting. In this setting, the cross-border element, i.e. the integration of markets, is largely absent which is why EU energy law is less prescriptive. Yet, Directive 2019/944/EU seems to set a new emphasis on decentral options for the energy transition. The formal recognition of energy communities, i.e. $\mathrm{CEC}$, is one example that new actors are becoming a more prominent role in this transition. One of the innovative elements of CEC is that they potentially may be open to cross border participation. The following sections present the EU legal framework on CEC, including the crossborder aspect.

\subsection{Citizen energy communities}

Generally, the term "energy community" covers a wide range of initiatives of a variety of actors which engage in some form of organisation in activities in the energy sector. In the EU context, the origins are often ascribed to environmentalist movements of the 1970s which envisioned a reorganisation of the energy sector as driven by antinuclear sentiments and as a response to the oil crisis [28]. On the more recent emergence of energy communities, research aimed at analysing which factors exactly distinguish energy communities from conventional other activities in the energy sector and suggests how to categorise energy communities [29]. Two key dimensions are identified and suggested: a process dimension which determines who is involved and who exercises influence and an outcome dimension which determines how outcomes of an initiative are spatially and socially distributed, essentially organizing who benefits in economic and social terms. The research subsequently emphasises that these dimensions are not about defining a specific technology but "social arrangements through which a given technology, irrespective of its scale or cost, is being implemented and made useful" [29]. Various actors from the private and the public sector could be involved to different extents and add to- or form a community [30].

While energy communities already existed in various EU MS, they were not formally recognised by EU legislation until the adoption of Directive 2018/2001/EU which introduced "renewable energy communities" [31] and Directive 2019/944/EU which introduced "citizen energy communities" [15]. Generally, CEC may encompass more activities and are less restricted in terms of proximity requirements and energy source, which is why REC can be considered a subcategory of CEC [32, 33]. Both concepts include an option for "cross-border participation" (art. 16(2a) Directive 2019/944/EU and art. 22(6) Directive 2018/2001/EU). As the definition of CEC is wider, the remainder of this article refers to CEC. The definition of CECs establishes four main elements, the legal form of CEC, its governance, purposes, and potential activities. The following Table 1 summarises the legal definition.

The following sections explains these elements further before discussing the option for CECs to function across national borders.

\subsubsection{Governance, activities, and purpose}

The definition of CEC is very broad in all aspects (governance, purpose, activities) which allows for a wide variety of CECs. Yet, local energy systems and related activities do not automatically constitute a CEC and Directive 2019/944/EU even states that "the definition of citizen energy communities does not prevent the existence of other citizen initiatives such as those stemming from private law agreements." (recital 44). MS can thus choose to also allow other types of market actors to start activities on local energy systems, which do not fall under the scope of CECs. This is important in order to understand that organizing activities related to local energy systems are not automatically a CEC, but only if these activities are organized in a way which complies with the eligibility criteria of CECs. In line with the research aiming to distinguish energy communities from conventional other activities in the energy sector, the two main eligibility criteria relate to the governance (i.e. who is involved and who exercises influence) and the purpose (i.e. how are outcomes spatially and socially distributed) [29].
Table 1

Definition of "citizen energy communities" (art. 2(11) Directive 2019/944/EU).

\begin{tabular}{|c|c|c|c|}
\hline Element & $\begin{array}{l}\text { Legal text article } 2 \\
\text { (11) Directive 2019/ } \\
\text { 944/EU }\end{array}$ & Explanation & $\begin{array}{l}\text { Obligatory for } \\
\text { implementation in } \\
\text { national law }\end{array}$ \\
\hline Form & Legal entity that ... & $\begin{array}{l}\text { No specific legal } \\
\text { form, but dedicated } \\
\text { entity }\end{array}$ & yes \\
\hline Governance & $\begin{array}{l}\text { - is based on } \\
\text { voluntary and open } \\
\text { participation and is } \\
\text { effectively controlled } \\
\text { by members or } \\
\text { shareholders that are } \\
\text { natural persons, local } \\
\text { authorities, including } \\
\text { municipalities, or } \\
\text { small enterprises; }\end{array}$ & $\begin{array}{l}\text { Effectively } \\
\text { controlled by } \\
\text { members, variety } \\
\text { of actors from } \\
\text { public and private } \\
\text { sector }\end{array}$ & yes \\
\hline Purpose & $\begin{array}{l}\text { - has for its primary } \\
\text { purpose to provide } \\
\text { environmental, } \\
\text { economic or social } \\
\text { community benefits } \\
\text { to its members or } \\
\text { shareholders or to the } \\
\text { local areas where it } \\
\text { operates rather than } \\
\text { to generate financial } \\
\text { profits; }\end{array}$ & $\begin{array}{l}\text { Rather value than } \\
\text { profit-driven } \\
\text { Benefits can be } \\
\text { distributed broadly } \\
\text { (members, } \\
\text { shareholders, } \\
\text { region) }\end{array}$ & yes \\
\hline Activities & $\begin{array}{l}\text { - may engage in } \\
\text { generation, including } \\
\text { from RES, } \\
\text { distribution, supply, } \\
\text { consumption, } \\
\text { aggregation, energy } \\
\text { storage, energy } \\
\text { efficiency services or } \\
\text { charging services for } \\
\text { electric vehicles or } \\
\text { provide other energy } \\
\text { services to its } \\
\text { members or } \\
\text { shareholders; }\end{array}$ & $\begin{array}{l}\text { No specific activity, } \\
\text { non-exhaustive list }\end{array}$ & open to MS \\
\hline
\end{tabular}

The eligibility criteria relating to the governance of CECs requires the establishment of a dedicated legal entity which is effectively controlled by its members and shareholders. The definition does not further specify which measures are required to comply with the condition "effective control", but it might, for example, relate to voting rights, democratic appointment of members of supervisory board, and/or majority shareholding. Membership of CEC has to be open and voluntary. Members could include a variety of different actor categories, are natural persons, local authorities, including municipalities, or small enterprises. It is not clear whether "citizens", as the name suggests, have to be directly included (or at least represented) in CECs. Important to mention is that in case residential customers are members they do not lose their rights as customers (art. 16(1 c)). In turn this means that if the CEC acts as a supplier or as DSO, they have to guarantee all associated rights of small consumers (households and SMEs).

The eligibility criterion relating to the purpose that CEC need to fulfill requires that CECs have to provide "environmental, economic or social community benefits to its members or shareholders or to the local areas where it operates", as opposed to financial profits. This is a very broad requirement and yet essential in distinguishing CEC from conventional actors in the sector. However, it is not clarified who decides on the desired "community benefit" and whether and how those are achieved. This article proposes system cost savings as a measure for benefits. It is investigated whether and how linking distribution systems across national borders via a switch can contribute to system cost savings (section 4). In other words, whether CBC in the form of cross-border CEC can be a potential source of community benefits. 


\subsubsection{Relation with distribution system operators}

As one of the potential tasks of CEC could be distribution system operation, Directive 2019/944/EU provides several options for organizing the relation with the DSO. As a minimum requirement MS are obliged to ensure that DSOs "cooperate with CECs" and facilitate the transfer of electricity "within CECs" for a "fair compensation" from the CEC. In addition to this option of "cooperation between DSOs and CECs" MS have the option to allow "CECs to autonomously manage distribution networks". In this case, the proximity condition of members of the CEC has to be fulfilled, as they would then have the right to manage distribution systems in "their areas of operation". This is also further illustrated by the conditions if such a right is granted to CECs which mainly refer to the regulation of connection points with neighboring networks (art. 16(4 a-b)). Under this option, MS may also decide to grant specific exemptions to CECs including the rules on the procurement of energy to cover losses and non-frequency ancillary services in its system, the requirement that tariffs, or their methodologies, are approved prior to their entry into force, the requirements to procure flexibility services and to develop the system on the basis of network development plans, and the requirements not to own, develop, manage or operate recharging points for electric vehicles and energy storage facilities. These exemptions would grant the operator of the CEC (either the DSO or the CEC acting as DSO) considerable leniency in the development, the operation, and the charging of network tariffs.

Overall, Directive 2019/944/EU leaves a large degree of discretion to the MS in determining the relation between CECs and DSOs. Some MS might exclude system operation from the potential task package of CECs and other might allow CECs to autonomously operate systems and possibly also grant them special exemptions in their national legal frameworks. The implementation is not only relevant for the role of CECs, but is just as important for DSOs. All DSOs will have to prepare to at least cooperate with CECs.

\subsubsection{Functioning across national borders}

In general, the definition of CEC does not include a proximity element which means that CECs are in principle not bound by a confined geographical area or grid. MS may decide to allow CECs to be open to "cross-border participation" (Art. 16(2 a) Directive 2019/944/EU). Preceding draft versions of the directive were clearer that the cross-border element not only entails membership, but the actual activities of the CEC. The proposal for the directive published by the EU Commission in 2016 included the "cross-border element" even in the definition and clearly linked the activities thereto by stating: "[...] local energy community $[. .$.$] involved in distributed generation and in performing activities of$ a DSO, supplier or aggregator at local level, including across borders." (art. 2 (7) proposal for a Directive). This is less clear in the adopted version of the directive and the question is thus not only whether MS implement the cross-border element in their national legal frameworks, but also how they establish "participation" in this context. Furthermore, different implementation at MS level might lead to uncertainty, especially when neighboring countries implement two contradicting forms of CEC.

The adoption of CEC in the EU legal framework and the option that CEC may be open for "cross-border participation" raises the question how a cross-border CEC could be implemented. As it is one of the core legal requirements that CEC provides "community benefits for its members or the wider area where it operates" this becomes a determining factor for identifying a viable technical option. Directive 2019/944/EU leaves much room for the implementation of "community benefits", which can be economic, social or environmental in nature. For the purpose of this article, which aims at investigating the option of linking distribution systems across borders as means to expand grid capacity and flexibility to integrate RES connected to the distribution grid, the community benefit is defined by system cost savings (the exact calculation method is explained in section 4). While it is beyond the scope of this article to provide a detailed technical analysis of options from an engineering perspective, the following section sketches some ideas how infrastructure could be linked on distribution system level across borders.

\section{Technical options: cross-border connections on distribution system level}

The most obvious option for a cross border connection would be to connect distribution systems across national borders. For this a direct current (DC) line may be a solution [34], which however would imply significant costs. In case of electricity transfers over long distances, using such DC links might be an economically viable option. (see e.g. the field of connecting offshore wind farms [35]). While this option seems to be most straightforward, it implies electricity flows between the two distribution systems which are hard to predict and control leading to operational challenges for the respective DSOs and TSOs. The purchase and procurement of balancing and control energy would be significantly affected, so that the DSOs and TSOs would have to closely cooperate and may even no longer be able to guarantee a stable and reliable grid operation.

A somewhat more restricted option for a cross-border connection between two MS could be the connection of a producer and a consumer by an islanded direct cable. Islanded here means that only one producer or consumer in one MS gets connected to a distribution grid in another MS. While such a setting is likely to be technically less problematic and less costly than connecting two distribution systems, also the potential benefits for solving congestion problems in the system by such a connection are very limited. A direct cable connecting a RES generation installation with a consumer would only extend the electricity grid of one MS to the territory of the neighboring MS. This is currently already the case in some regions with special geographical properties such as valleys surrounded by high mountains. It only facilitates the integration of this single production site and does not contribute to solving the structural problem of congestion resulting from intensified use of the distribution system.

Considering the limitations of the mentioned options, this article proposes a novel approach, namely to link distribution systems via a "switchable element". Fig. 1 shows the conceptual idea of linking two distribution systems with a "switchable element". This cross-border element can entail generation, (flexible) consumption, but also twoway flexibility assets (storage) and it has switchable connections to two different distribution systems, i.e. one for the connection to the distribution system of the region in MS 1 and another for the connection to the distribution system of the region in MS 2. In this way, the switchable element is shared between the two regions and thus both have the ability to use the flexibility present in the cross-border element. The exact location of the switchable element, i.e. whether it is placed exactly on the border or in one of the two MS, would not matter, as long as it can be connected to the distribution systems in both MS. In any case, this installation would not qualify as an "interconnector" as established in EU legislation as this definition refers to the interconnection of transmission systems. However, what is indeed relevant to consider for the location are the distances to the respective distribution grids as shorter distances would most likely imply lower connecting charges as set by national energy law. This also relates to an additional cost, as the operator of the switchable element (for example a CEC) would need to bear the costs for constructing and maintaining two

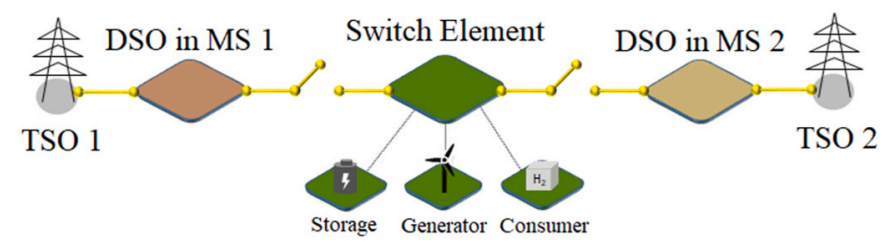

Fig. 1. Switchable cross-border element. 
connections. While the exact calculation of the costs related to the construction of infrastructure goes beyond the scope of this article, the additional costs for connection need to be outbalanced by the potential income for providing flexibility services.

Due to current regulations and also technical issues, this article presents a situation where the switchable element can be connected either to the region in MS 1 or to the region in MS 2, but never to both at the same time. As both connections are never used at the same time, this implies that the distribution systems are never directly connected. The main idea is that the element can temporarily provide additional flexibility to the connected systems for specified time periods, i.e. in $15 \mathrm{~min}$ intervals when needed. Note that compared to the concept of an islanded direct cable both regions are still connected to their national transmission system.

Implementing such a switchable element could facilitate $\mathrm{CBC}$ at the local level for the energy transition. Ideally, the switchable element would then offer additional flexibility, i.e. helping to resolve congestion or providing generation, and thus result in potential benefits for both regions.

In order to determine which elements (generation, flexible consumption, or battery storage) provide the highest economic benefit in terms of system cost savings for both regions, the elements are considered separately, i.e. either a wind turbine, or a flexible consumer, or a battery storage asset. The following section focuses on the corresponding calculation of potential economic benefits of a cross-border CEC using a "switchable" link.

\section{Switching capacity across borders: quantifying economic benefits of CEC}

To investigate the potential of cross-border CEC for the purpose of integrating RES and alleviating congestion at distribution system level, this article focuses on system cost savings as a measure for generating economic benefits. In order to quantify the potential economic benefits of linking distribution systems across borders via a switch element, an optimization model is proposed. The model objective is to minimize the total electricity system cost of the cross-border region by using the switch element in an appropriate way. The following section explains the modelling approach in more detail.

\subsection{Modelling approach}

Matching generation and demand locally, i.e. at the distribution system level, has the potential to reduce costs also at transmission system level. The avoided costs and additional benefits at the transmission grid level may be quantified on the basis of the electricity system costs. Existing research provides various methodologies for calculating these electricity system costs [36-40]. This research builds on the methodology given in Ref. [39].

For the electricity system costs a distinction is made between costs resulting from the infrastructure required on transmission grid level and costs incurred by the redispatch and curtailment of RES. The infrastructure costs on TSO level (further referred to as "transmission grid infrastructure cost") include all annual investment and operational expenditures required for a stable and reliable transmission grid operation. Redispatch and curtailment costs arise from a lack of transmission grid capacities, which requires the temporal curtailment of RES feed-in in order to prevent the transmission system from overloads and blackouts. The total electric system costs $C_{\text {Sys }}(r)$ of a region $r$ now are defined as:

$C_{\text {Sys }}(r)=c_{\text {Capacity }}(r) * P_{\text {Max }}(r)+c_{\text {Cur }}(r)^{*} V_{\text {feed,RES }}(r) * \alpha$

The transmission grid infrastructure costs are calculated from the grid tariffs $c_{\text {Capacity }}(r)$ of the respective TSO and the maximum grid demand/feed-in per region and time period $P_{M a x}(r)$. Governmental institutions in both neighboring countries regulate the calculation of these grid usage fees. Thus, the grid fees can be used as a reliable proxy for the specific transmission grid infrastructure costs.

For the calculation of the curtailment and redispatch costs it is assumed that at the transmission grid level on a yearly base a certain fraction $\alpha$ of the total electricity feed-in from renewables $V_{\text {feed,RES }}(r)$ has to be curtailed. Thus, a reduced feed-in of RES to the transmission grid consequently should lead to a lower curtailment of electricity and lower redispatch. The specific curtailment costs $c_{C u r}(r)$ represents the respective annual TSO costs for renewable curtailment and redispatch measures.

The calculated infrastructure cost savings are not monetary, but only calculated based on the change in grid usage. The core reason for this is that in a meshed electricity transmission grid, it is hard or even impossible to attribute needed grid investments to specific individual grid users.

Using these cost elements, the developed model steers the connection of the switchable element to the two MS over time and its use in order to minimize the total electricity system costs of the entire cross-border region which are made up of the individual system costs of the two connecting areas. This model does not take into account wholesale electricity market prices, but is exclusively based on system operation costs. A market-based optimization would lead to other results. Also note that the costs for building and operating the switchable element are not included in the total electricity system costs. The presented system cost calculation methodology only considers the costs on the transmission grid level. Since the introduced switchable element connects two distribution grids, these costs are not part of the electricity system cost. These additional expenditures have to be covered locally. The model is implemented in the programming language Python and uses the Pyomo library with the CPLEX solver for optimization.

For the calculation of the additional costs and benefits of a crossborder connection a comparison of isolated and connected power system states is performed. In the isolated scenario, the model is used to calculate the electricity system cost for each region without an electricity connection on the border.

\subsection{Case study}

The idea to link distribution systems across national borders in the EU emerged in 2015 among stakeholders in a cross-border region between the Netherlands (municipality of Emmen) and Germany (municipality of Haren). While Emmen has a high electricity demand due to industrial consumers, Haren has occasional high surpluses of electricity produced on the basis of RES, in particular wind energy. Jointly, the municipalities initiated the "Smart Energy Region Emmen-Haren" project (SEREH). The idea was to establish a local energy system functioning across the border on distribution grid level, which facilitates the efficient matching of supply and demand on a local scale.

Table 2 shows the specific model input parameters for the two bordering regions. The underlying data has been provided by the SEREH project.

Note, that the annual electricity demand from Region 1 is more than twice than that of Region 2. This is mainly due to the higher number of inhabitants in Region 1 and the considerably larger industrial sector. Geographically, the area of Region 1 is approximately $40 \%$ larger than that of Region 2, so the annual demand per $\mathrm{km}^{2}$ of Region 1 is about $26 \%$ higher than that of Region 2. More generally speaking, Region 1 can thus be classified as "urban high load" and Region 2 as the "rural low load" region. Despite the different annual electricity demands and load patterns, the annual electricity generation from RES is almost the same in both regions. In the "urban high load" region, the local electricity production from RES exceeds its annual demand by $19 \%$, while in the "rural low load" region it is $141 \%$. The RES generation in the "urban high load" region mainly comes from large-scale solar parks, while the "rural low load" region produces most of its electricity from wind.

This article investigates whether the two regions can economically 
Table 2

Model input parameter.

\begin{tabular}{|c|c|c|c|}
\hline Parameter & Unit & Region in MS 1 & Region in MS 2 \\
\hline \multicolumn{4}{|l|}{ Electricity Demand } \\
\hline Total Consumption & [MWh/a] & 385,688 & 183,655 \\
\hline Min. Demand & [MW] & 20.34 & 4.86 \\
\hline Max. Demand & [MW] & 78.67 & 43.12 \\
\hline \multicolumn{4}{|l|}{ Renewable Generation } \\
\hline Total Generation & [MWh/a] & 459,343 & 441,911 \\
\hline Solar & [MWh/a] & 154,549 & 23,421 \\
\hline Wind & [MWh/a] & 304,794 & 365,002 \\
\hline Biomass & [MWh/a] & - & 53,488 \\
\hline Min. Generation & [MW] & 0.00 & 6.11 \\
\hline Max. Generation & [MW] & 230.62 & 160.57 \\
\hline \multicolumn{4}{|l|}{ Renewable Capacities } \\
\hline Solar & [MW] & 181.72 & 26.56 \\
\hline Wind & [MW] & 95.00 & 141.10 \\
\hline Biomass & [MW] & 0.00 & 8.44 \\
\hline \multicolumn{4}{|l|}{ System Cost Parameter } \\
\hline Infrastructure TSO Cost & {$\left[€ /\left(M W^{* a} a\right)\right]$} & 50,000 & 50,000 \\
\hline Curtailment Price & {$[€ /(M W h * a)]$} & 50 & 50 \\
\hline $\begin{array}{l}\text { Curtailment Avoidance Rate } \\
\quad \alpha\end{array}$ & {$[\%]$} & 5 & 5 \\
\hline
\end{tabular}

benefit from their complementary characteristics. As stated in Section 4.1, economic benefits are quantified in terms of system cost savings. The idea is to connect the regions with a switchable element which is owned by one CEC with members from both regions. Members could be public entities, SMEs, and natural persons. Both regions can temporarily use the additional flexibility provided by the respective switchable element, but the overall gain needs to be managed and distributed by the CEC.

Three different connection elements (wind turbines, electrolyser, and battery storage) are separately analysed in terms of potential system cost savings. Depending on the type of switchable asset, the capacities of the respective flexibility options from both regions are part of the crossborder element and thus switchable. For the switching of wind turbines, we assume that 29.4 MW wind capacity from each of the regions is switchable and now part of the cross-border element. Thus, the total switchable RES generation capacity of the shared element is $58.8 \mathrm{MW}$. If the switchable cross-border asset is an electrolyser, the total switchable capacity is assumed to be $20 \mathrm{MW}$, since each of the two regions has a 10 MW electrolyser. In the case of a switchable battery, the battery size is fixed to $10 \mathrm{MWh}, 5 \mathrm{MWh}$ from each region. For reference, the two regions are also modelled without an electricity connection at the border. In this case, the system costs for both regions are optimized individually without a cross-border interconnection. Thus, imbalances in the distribution grids can only be balanced using the transmission grids. The operating modes of the electrolysers and battery storages within the respective regions are determined by the system cost minimization of the model. Electrolysers and batteries are then used to reduce the maximum annual demand/feed-in and curtailment of RES generation for each region. To achieve comparable model results which are independent of different price structures, the same system cost parameter for infrastructure and curtailment costs are applied to both regions. Cost savings are only realized by differences in the structure of the regions such as supply and demand profiles. The following section presents the results.

\subsubsection{Model results}

Fig. 2 shows the switching times of the switchable elements and the corresponding cross-border electricity flows for a typical day in March.

This figure furthermore shows the utilization of the cross-border connection in terms of the amount of times the direction switches and the volume of electricity transmitted.

The generation unit switches between 8 a.m. and 2 p.m., but due to low wind speed only a small quantity of electricity is transferred across the border. Between 7 p.m. and 9 p.m., generation is switched from the rural "low load" region to the "urban high load" region and the quantity of electricity transferred reaches its daily maximum of approximately 15 MW. In the "urban high load" region, the electricity is either consumed directly by the local demand, converted into hydrogen, stored in a battery or fed into the transmission grid. The electrolyser unit, i.e. a flexible consumer, is connected to the "urban high load" region between 6 a.m. and 4 p.m. During this time period, the electricity production from solar reaches its maximum and electricity surpluses are converted into (green) hydrogen. The higher electricity production on the basis of wind explains why in the evening, the electrolyser is connected to the "rural low load" region which has installed more wind turbines (see Table 2). During this time period, the electrolyser runs at its full capacity of $20 \mathrm{MW}$. The battery storage asset changes the direction of connection with a high frequency between $10 \mathrm{a} . \mathrm{m}$. and $4 \mathrm{p} . \mathrm{m}$. First it connects to the "urban high load" region and charges with full power. Afterwards it connects to the "rural low load" region and discharges with maximum
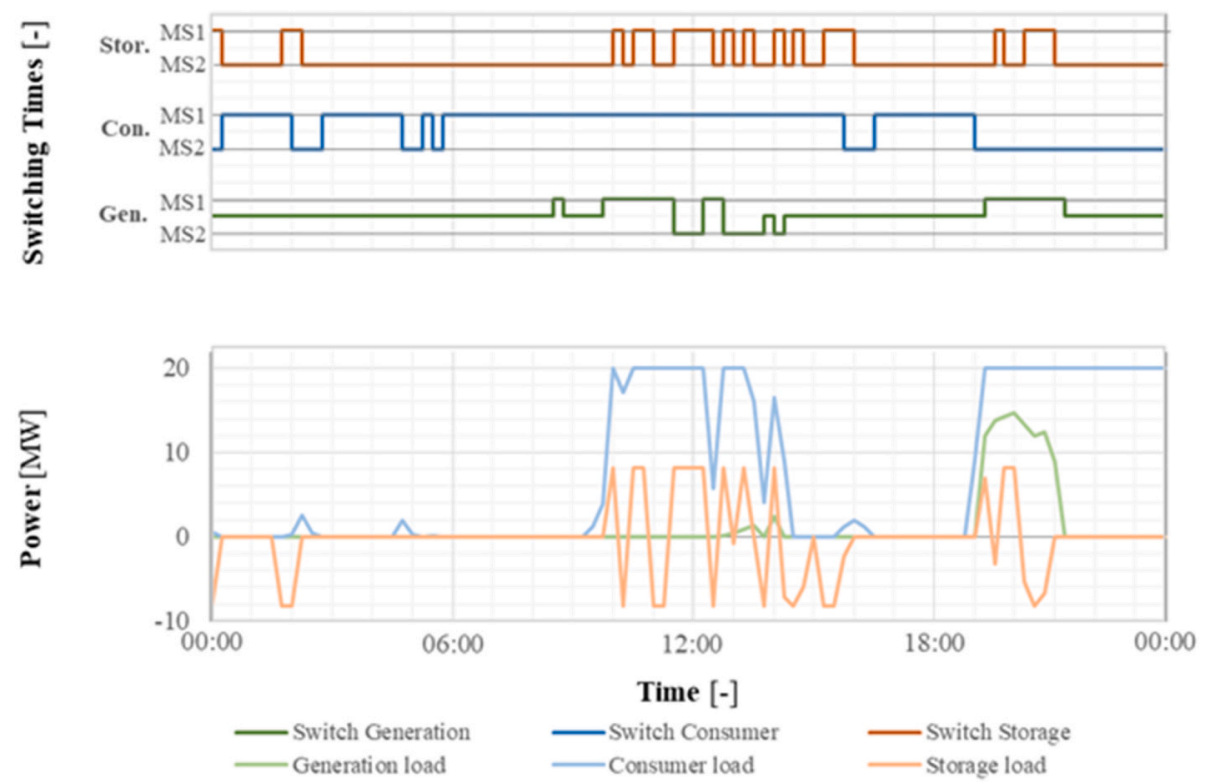

Fig. 2. Switching times for a typical day in March. 
power. This repeats several times until about 2.30 p.m., and can be seen as a transfer of local generation surpluses from the "urban high load" region to the "rural low load region".

Over the time of a complete year, RES generation plants are switched across the border $29 \%$. Of this share the large majority is wind capacity which is switched from the "rural low load" region to the "urban high load" region (22\%). The remaining $7 \%$ is wind capacity which is switched from the "urban high load" region to the "rural low load" region. Overall, this increases local RES consumption and thus reduces the transmission system usage. It also provides additional grid capacity for production based on RES and load. The electrolyser connects $55 \%$ of the time of the year to the "rural low load" region. The direction of connection changes 3103 times per year indicating that the connection to a region remains on average $2.8 \mathrm{~h}$. The connection direction of the battery changes, compared to the electrolyser, with a higher frequency. The battery connects for the large majority of the time of a year to the "rural low load" region (about 83\%) and it is switched 5764 times a year, which corresponds to connection duration of $1.5 \mathrm{~h}$ on average. Table 3 compares the calculated system costs for the isolated scenario (no switching element installed) and the switchable cross-border elements (producer, flexible consumer and storage). The system cost savings are calculated in comparison to the reference scenario where there is no connection at the border.

Fig. 3 illustrates the total system costs for the reference scenario and the switchable cross-border elements, Fig. 4 the corresponding percentage cost savings.

Due to the different sources of renewable energy in the two regions the total electricity system costs of the "urban high load" region (solar) are higher than the one of the "rural low load" region (wind). This leads to higher transmission grid feed-in peaks. The total electricity system costs of the two border regions in the reference scenario are $15.68 \mathrm{mln}$. $€ /$ a.

Regardless how the two regions are linked, i.e. which switchable asset is deployed, linking leads to system cost savings. The different elements differ considerably in terms of the distribution of system cost savings.

Model results depict that the highest system benefit is achieved by switching electricity generation between the two regions. This leads to a reduction of both, total transmission grid infrastructure and redispatch and curtailment costs. Transmission grid infrastructure costs decrease by $3.96 \%$, costs for redispatch and curtailment by $3.88 \%$. Cost savings are, however, distributed unevenly between the two regions. While transmission grid infrastructure costs in the "rural low load" region decrease by approximately $12 \%$, the costs of the "urban high load" region increase by about $2 \%$. There is no reduction of the redispatch and curtailment costs in the "urban high load region". The benefits of linking the regions

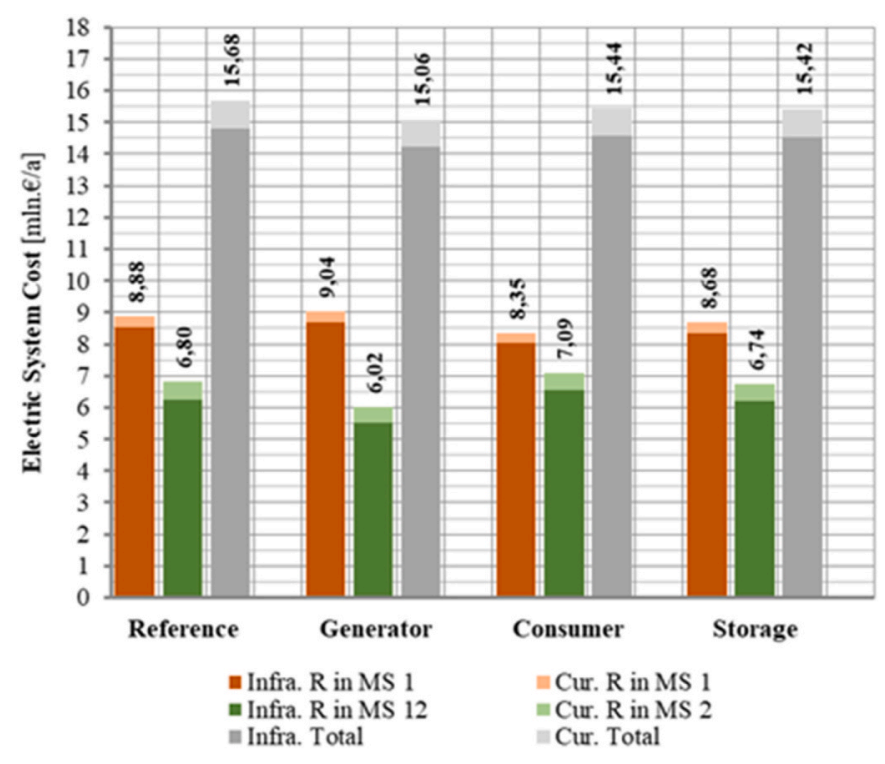

Fig. 3. Total system costs.

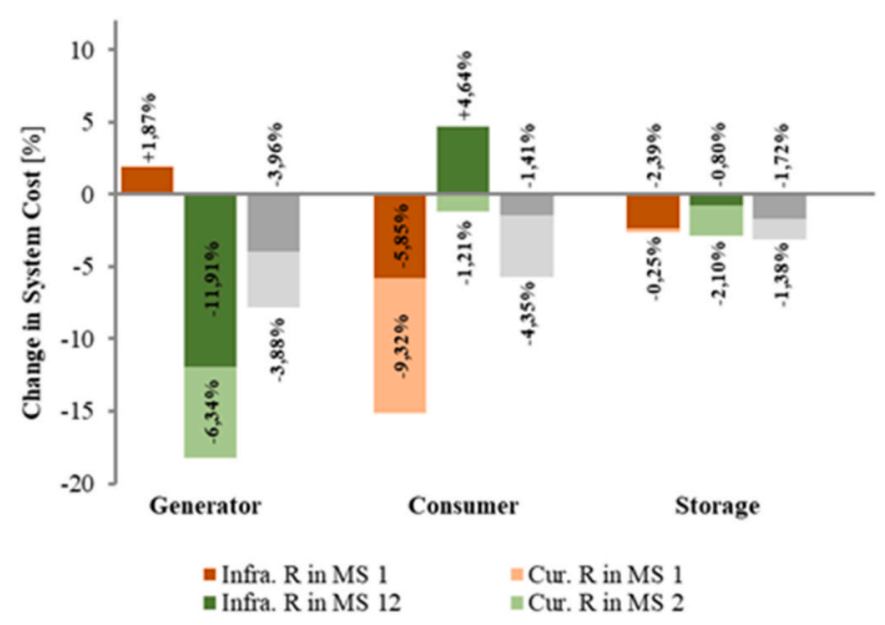

Fig. 4. System cost savings.

Table 3

System cost model results.

\begin{tabular}{|c|c|c|c|c|c|c|c|}
\hline \multirow[t]{2}{*}{ Key Figure } & \multirow[t]{2}{*}{ Unit } & \multicolumn{2}{|c|}{ Region in MS 1} & \multicolumn{2}{|c|}{ Region in MS 2} & \multicolumn{2}{|l|}{ Total } \\
\hline & & Abs. & Change & Abs. & Change & Abs. & Change \\
\hline \multicolumn{8}{|l|}{ Isolated Scenario } \\
\hline Infrastructure TSO Cost & [mln.€/a] & 8.54 & - & 6.26 & - & 14.79 & - \\
\hline Curtailment Cost & [mln.€/a] & 0.34 & - & 0.54 & - & 0.89 & - \\
\hline Total & [mln.€/a] & 8.88 & - & 6.80 & - & 15.68 & - \\
\hline \multicolumn{8}{|l|}{ Generator } \\
\hline Infrastructure TSO Cost & [mln.€/a] & 8.70 & $+1.87 \%$ & 5.51 & $-11,91 \%$ & 14.21 & $-3.96 \%$ \\
\hline Curtailment Cost & [mln.€/a] & 0.34 & $0 \%$ & 0.51 & $-6.34 \%$ & 0.85 & $-3.88 \%$ \\
\hline Total & [mln.€/a] & 9.04 & $+1.80 \%$ & 6.02 & $-11.46 \%$ & 15.06 & $-3.95 \%$ \\
\hline \multicolumn{8}{|l|}{ Consumer } \\
\hline Infrastructure TSO Cost & [mln.€/a] & 8.04 & $-5.85 \%$ & 6.55 & $+4.64 \%$ & 14.58 & $-1.41 \%$ \\
\hline Curtailment Cost & [mln.€/a] & 0.31 & $-9.32 \%$ & 0.54 & $-1.21 \%$ & 0.85 & $-4.35 \%$ \\
\hline Total & {$[\mathrm{mln} . € / \mathrm{a}]$} & 8.35 & $-5.99 \%$ & 7.09 & $+4.17 \%$ & 15.44 & $-1.58 \%$ \\
\hline \multicolumn{8}{|l|}{ Storage } \\
\hline Infrastructure TSO Cost & [mln.€/a] & 8.33 & $-2.39 \%$ & 6.21 & $-0.80 \%$ & 14.54 & $-1.72 \%$ \\
\hline Curtailment Cost & [mln.€/a] & 0.34 & $-0.25 \%$ & 0.53 & $-2.10 \%$ & 0.88 & $-1.38 \%$ \\
\hline Total & {$[\mathrm{mln} . € / \mathrm{a}]$} & 8.68 & $-2.31 \%$ & 6.74 & $-0.90 \%$ & 15.42 & $-1.70 \%$ \\
\hline
\end{tabular}


via a switchable generation would thus result in benefits for the "rural low load region".

Linking the two regions via a flexible consumer also leads to overall system cost savings. Here, the transmission grid infrastructure costs in the "rural low load" region increase by $4.64 \%$, while the "urban high load region" benefits as transmission grid infrastructure costs decrease by $5.85 \%$.

The lowest overall system cost reduction results from connecting the regions via a storage asset. Total system cost amounts to $15.42 \mathrm{mln}$. $€ / \mathrm{a}$. This corresponds to a cost reduction of $1.70 \%$ compared to the reference case. Compared to the other two options (connection via generation and flexible consumer), system cost savings are distributed more evenly between the regions as both regions achieve reduced transmission grid infrastructure and reduced redispatch and curtailment costs. In the "urban high load" region, main cost savings result from reduced transmission grid infrastructure cost, while in the "rural low load" region reduction stem from savings in redispatch and curtailment cost.

\section{Discussion}

This article hypothesised that in the field of energy at the local level, i.e. the distribution system level, CBC can generate benefits helping cross-border regions to thrive. This particular focus was justified by two general assumptions about cross-border regions, namely that they are typically less developed in economic and infrastructural terms and that they often may show complementary characteristics in terms of generation on the basis of RES and electricity load.

Findings show that especially the complementarity of the two bordering regions of the considered case study is the source of benefits in terms of system cost savings. More specifically, all investigated options of the "switchable element" lead to a decrease of electricity system costs. However, the amount and the distribution of the calculated system cost savings, and thus potential benefits for a cross-border CEC, highly depends on the type of switchable asset connecting the bordering regions. A "switchable generation installation" and a "switchable flexible consumer" both reduce total costs, but imply that the benefits are unevenly distributed between the two regions. While the "switchable production installation" provides benefits for the "rural low load region", the "switchable flexible consumer" provides benefits for the "urban high load region". Only the "switchable storage facility" would lead to benefits in terms of system cost savings for both regions, but also resulting in the lowest overall benefit. Achieving the highest overall cost savings thus does not correspond with the option where benefits are more evenly distributed. To resolve the problem of the uneven distribution between the regions, the additional system benefits need to be converted into remunerations for the CEC. The CEC could use the benefits for the advantage of the entire cross-border region in the interest of its members and shareholders, essentially contributing to $\mathrm{CBC}$ in the field of energy at the local level.

Beyond the case of cross-border regions, the findings show that connecting regions with complementary properties regarding electricity generation and demand (e.g. urban-rural or industrial-residential) via a switchable element leads to a better allocation of transmission grid capacities and generally a more efficient utilization of the system. In that sense, the proposed approach could also be relevant on a national level. Nevertheless, it is suspected that complementarity regions can be found particularly often in international cross-border areas and thus yield the higher benefits.

This article presented first ideas how to enhance CBC at the local level for the energy transition from an EU law and economic perspective. Researching the possibilities for such a cross-border CEC at implementation level is beyond the scope of this article, but can be subject to further research in specific contexts. Several points remain for further research investigating the concrete implementation in specific contexts: The optimization model developed within this research is limited to the economic perspective and thus is not applicable for technical implementation planning, such as the type of power transmission between MS (AC/DC), the technical design of the switch circuits or the dimensioning of cables and cable routes. For this reason, the model also does not include the investment and/or operating costs of such a crossborder connection. From a legal perspective, it would be necessary to investigate the regulations on grid connections, potential support schemes, and other costs which might be charged from system users in the respective countries.

\section{Conclusions}

This article is set out with the aim to investigate EU legal options and potential economic benefits of $\mathrm{CBC}$ at the local level for the energy transition. The EU legal framework provides CEC as a new concept, which, potentially, is open for "cross-border participation". As EU MS are currently implementing CEC in their national legal frameworks, they can decide whether to include the cross-border element or not. The question this article investigated is whether $C B C$ via $C E C$ could be a source of additional benefits in terms of system cost savings. The overall results of the model calculation show that connecting distribution systems via a switchable element, regardless whether the element includes generation, a flexible consumer, or storage, leads to better system utilization and thus system cost savings. However, calculated system cost savings can not only be used as an indicator for economic benefits of such an electricity connection at distribution system level. Rather, results prove that using switchable elements for coupling regions with complementary properties regarding generation and consumption of electricity (as in the case study two regions of two MS, but this could possibly also apply to two different distribution grids within one country) have the potential to increase the (international) electricity transfer capacities in the EU electricity system and to reduce the need for additional grid capacities in the transmission grid. Yet, the results also show that the distribution of benefits strongly depends on the switchable element and that the option yielding the highest overall benefit may not correspond to the option where benefits are evenly distributed. This uneven distribution of benefits could be mitigated by the organisation via a cross-border CEC which distributes benefits to "its members or shareholders or the wider region where it operates", as it is requested by the provisions on CEC as established by Directive 2019/944/EU. In this way, the CEC is an organisational instrument to redistribute the benefits yielded by the switchable element in a more equal way, i.e. for the border community. This finding can inform national legislatures when implementing CEC in their national legal frameworks in the following way: CEC should be open to cross-border participation and CECs should receive financial remuneration for contributing to system cost savings. Considering these points when designing the legal framework for CEC at national level would be a precondition for enhanced $\mathrm{CBC}$ at the local level for the energy transition. In addition, CEC functioning across the border could contribute to strengthening structurally weak border regions. Another relevant finding for national policy and lawmakers is the need to incentivise flexibility services and cost-efficient distribution system operation. EU legislation opens the pathway to increasingly use flexibility at distribution system level [see art. 32 in 15]. For solutions allowing for flexibility in the system, such as the switchable element, it is a necessary precondition that flexibility is incentivised, for example via network tariffs, and that DSOs are obliged to consider flexibility sources as an alternative to grid expansions.

\section{Credit author statement}

Andreas Stroink: Methodology, Software, Validation, Formal analysis, Investigation, Visualization. Lea Diestelmeier: Conceptualization, Investigation, Writing - original draft, Writing - review \& editing. Johann L. Hurink: Conceptualization, Methodology, Writing - review \& editing, Supervision. Tim Wawer: Conceptualization, Methodology, Writing - review \& editing, Supervision. 


\section{Declaration of competing interest}

The authors declare that they have no known competing financial interests or personal relationships that could have appeared to influence the work reported in this paper.

\section{Acknowledgments}

This research is conducted within the Smart Energy Region EmmenHaren (SEREH) project (151232) funded by the INTERREG V program of the European Union. The authors would like to thank all SEREH project partners and associated partners for their support.

\section{References}

[1] European Commission, Proposal for a directive of the european parliament and of the council amending Directive (EU) 2018/2001 of the European Parliament and of the Council, Regulation (EU) 2018/1999 of the European Parliament and of the Council and Directive 98/70/EC of the European Parliament and of the Council as regards the promotion of energy from renewable sources, and repealing Council Directive (EU) 2015/652. https://eur-lex.europa.eu/legal-content/EN/TXT/ HTML/?uri=CELEX:52021PC0557\&from=EN (accessed 11 January 2022).

[2] S. Henni, P. Staudt, B. Kandiah, C. Weinhardt, Infrastructural coupling of the electricity and gas distribution grid to reduce renewable energy curtailment, Appl. Energy 288 (2021), https://doi.org/10.1016/j.apenergy.2021.116597.

[3] K. Bell, S. Gill, Delivering a highly distributed electricity system: technical, regulatory and policy challenges, Energy Pol. 113 (2018) 765-777, https://doi. org/10.1016/j.apenergy.2021.116597.

[4] J. de Joode, J.C. Jansen, A.J. van der Welle, M.J.J. Scheepers, Increasing penetration of renewable and distributed electricity generation and the need for different network regulation, Energy Pol. 37 (2009) 2907-2915, https://doi.org/ 10.1016/j.enpol.2009.03.014.

[5] P. Olivella-Rosell, E. Bullich-Massagué, M. Aragüés-Peñalba, A. Sumper, S. $\emptyset$. Ottesen, J.A. Vidal-Clos, R. RobertoVillafáfila-Robles, Optimization problem for meeting distribution system operator requests in local flexibility markets with distributed energy resources, Appl. Energy 210 (2018) 881-895, https://doi.org/ 10.1016/j.apenergy.2017.08.136.

[6] R. Poudineh, T. Jamasb, Distributed generation, storage, demand response and energy efficiency as alternatives to grid capacity enhancement, Energy Pol. 67 (2014) 222-231, https://doi.org/10.1016/j.enpol.2013.11.073.

[7] K. Spiliotis, A.I. Ramos Gutierrez, R. Belmans, Demand flexibility versus physical network expansions in distribution grids, Appl. Energy 182 (2016) 613-624, https://doi.org/10.1016/j.apenergy.2016.08.145.

[8] European Commission, Joint Research Centre, K. Keramidas, M. Tamba, A. DiazVazquez, M. Weitzel, T. Vandyck, M. Tamba, S. Tchung-Ming, A. Soria-Ramirez, J. Krause, R. Van Dingenen, Q. Chai, S. Fu, X. Wen, Global Energy and Climate Outlook 2019: Electrification for the Low-Carbon Transition: the Role of Electrification in Low-Carbon Pathways, with a Global and Regional Focus on EU and China, 2020. https://data.europa.eu/doi/10.2760/58255. (Accessed 11 January 2022).

[9] P. Westerman, Breaking the circle: goal-legislation and the need for empirical research, Theory Practice Legislation 1 (2013) 395-414, https://doi.org/10.5235/ 2050-8840.1.3.395.

[10] P. Ringler, D. Keles, W. Fichtner, How to benefit from a common European electricity market design, Energy Pol. 101 (2017) 629-643, https://doi.org/ 10.1016/j.enpol.2016.11.011.

[11] M. Fürsch, S. Hagspiel, C. Jägemann, S. Nagl, D. Lindenberger, E. Tröster, The role of grid extensions in a cost-efficient transformation of the European electricity system until 2050, Appl. Energy 104 (2013) 642-652, https://doi.org/10.1016/j. apenergy.2012.11.050.

[12] K. Schaber, F. Steinke, T. Hamacher, Transmission grid extensions for the integration of variable renewable energies in Europe: who benefits where? Energy Pol. 43 (2012) 123-135, https://doi.org/10.1016/j.enpol.2011.12.040.

[13] L. Puka, K. Szulecki, The politics and economics of cross-border electricity infrastructure: a framework for analysis, Energy Res. Social Sci. 4 (2014) 124-134, https://doi.org/10.1016/j.erss.2014.10.003.

[14] J. Rumpf, H. Bjørnebye, Just how much is enough? Eu regulation of capacity and reliability margins on electricity interconnectors, J. Energy Nat. Resour. Law 37 (2019) 67-91, https://doi.org/10.1080/02646811.2018.1471802.

[15] DIRECTIVE (EU, 2019/944 OF THE EUROPEAN PARLIAMENT AND OF THE COUNCIL of 5 June 2019 on common rules for the internal market for electricity and amending Directive 2012/27/EU. https://eur-lex.europa.eu/legal-content/ EN/TXT/HTML/?uri=CELEX:32019L0944\&from=EN, 2019. (Accessed 11 January 2022).

[16] L. Diestelmeier, Citizen energy communities as a vehicle for a just energy transition in the EU - challenges for the transposition, Oil Gas Energy Law Intell. 1 (2020).
[17] M.M. Sokolowski, Renewable and citizen energy communities in the European Union: how (not) to regulate community energy in national laws and policies, J. Energy Nat. Resour. Law 38 (2020) 289-304, https://doi.org/10.1080/ 02646811.2020.1759247.

[18] A. Savaresi, The rise of community energy from grassroots to mainstream: the role of law and policy, J. Environ. Law 31 (2019) 487-510, https://doi.org/10.1093/ $\mathrm{jel} / \mathrm{eqz} 006$.

[19] M. Guillermo-Ramirez, The added value of European territorial cooperation. Drawing from case studies, in: E. Medeiros (Ed.), European Territorial Cooperation, Springer International Publishing, Basel, 2018, pp. 25-47.

[20] S. Svensson, P. Balogh, Limits to integration: persisting border obstacles in the EU, in: E. Medeiros (Ed.), European Territorial Cooperation, Springer International Publishing, Basel, 2018, pp. 115-134.

[21] B. Reitel, B. Wassenberg, J. Peyrony, The INTERREG Experience in Bridging European Territories. A 30-year Summary, The Urban Book Series, 2018, pp. 7-23, https://doi.org/10.1007/978-3-319-74887-0_2.

[22] L. De Sousa, Understanding European cross-border cooperation: a framework for analysis, J. Eur. Integrat. 35 (2013) 669-687, https://doi.org/10.1080/ 07036337.2012 .711827$.

[23] M. Aras, Territorial governance of EU cross-border renewable energy cooperation: a soluble or turbulent model in the current framework? Global Energy Law Sustain. 2 (2021) 79-97, https://doi.org/10.3366/gels.2021.0048.

[24] E.U. Regulation (, OF the EUROPEAN PARLIAMENT and of the COUNCIL of 5 June 2019 on the Internal Market for Electricity, 2019. https://eur-lex.europa.eu/lega l-content/EN/TXT/HTML/?uri=CELEX:32019R0943\&from=DE. (Accessed 11 January 2022), 2019/943.

[25] D. Newbery, G. Strbac, I. Viehoff, The benefits of integrating European electricity markets, Energy Pol. 94 (2016) 253-263, https://doi.org/10.1016/j. enpol.2016.03.047.

[26] C. Schoser, L. Sandberg, The regulation on cross-border electricity exchanges: substantive rules, in: J. Kettlewell, C. Jones (Eds.), EU Energy Law, Deventer, Claeys \& Casteels Publishing, 2020.

[27] European Union Agency for the Cooperation of Energy Regulators, ACER Market Monitoring Report 2019 - Electricity Wholesale Markets Volume, 2020. https:// documents.acer.europa.eu/Official_documents/Acts_of_the_Agency/Publication/ ACER\%20Market\%20Monitoring\%20Report $\% 202019 \% 20-\% 20$ Electricity $\% 20$ Wh olesale\%20Markets\%20Volume.pdf. (Accessed 11 January 2022).

[28] European Commission, Joint Research Centre, A. Uihlein, A. Caramizaru, Energy Communities: an Overview of Energy and Social Innovation, 2020. https://data.eu ropa.eu/doi/10.2760/180576. (Accessed 11 January 2022).

[29] G. Walker, P. Devine-Wright, Community renewable energy: what should it mean? Energy Pol. 36 (2008) 497-500, https://doi.org/10.1016/j.enpol.2007.10.019.

[30] E. Creamer, W. Eadson, B. van Veelen, A. Pinker, M. Tingey, T. Braunholtz-Speight, M. Markantoni, M. Foden, M. Lacey-Barnacle, Community energy: entanglements of community, state, and private sector, Geogr. Compass 12 (2018), e12378, https://doi.org/10.1111/gec3.12378.

[31] DIRECTIVE (EU), 2018/2001 of the EUROPEAN PARLIAMENT and of the COUNCIL of 11 December 2018 on the Promotion of the Use of Energy from Renewable Sources, 2018. https://eur-lex.europa.eu/legal-content/EN/TXT/HTM L/?uri=CELEX:32018L2001\&from=DE. (Accessed 11 January 2022).

[32] L. Diestelmeier, The role of energy communities in facilitating sustainable energy democracy: legal challenges, in: R. Fleming, K. Huhta, L. Reins (Eds.), Sustainable Energy Democracy and the Law, Brill | Nijhoff, Leiden, 2021, pp. 124-143.

[33] M. Jasiak, Energy communities - challenges for implementation of the EU legal framework, in: M. Roggenkamp, C. Banet (Eds.), European Energy Law Report XIV, Intersentia, Cambridge, 2021, pp. 197-218.

[34] D. Westermann, S. Schlegel, M. Malsch, R. Halbauer, F. Wirtz, M. Sturm, G. Kuhn, A. Krontiris, Distribution grid interconnection using DC-links, in: ETG Symposium, International ETG-Congress 2019, Esslingen, 2019, pp. 1-6.

[35] P. Bresesti, W.L. Kling, R.L. Hendriks, R. Vailati, HVDC connection of offshore wind farms to the transmission system, IEEE Trans. Energy Convers. 22 (2007) 37-43, https://doi.org/10.1109/TEC.2006.889624.

[36] T. Brown, D. Schlachtberger, A. Kies, S. Schramm, M. Greiner, Synergies of sector coupling and transmission reinforcement in a cost-optimised, highly renewable European energy system, Energy 160 (2018) 720-739, https://doi.org/10.1016/j. energy.2018.06.222.

[37] Y. Chen, H. Koduvere, P.A. Gunkel, J.G. Kirkerud, K. Skytte, H. Ravn, T.F. Bolkesjø, The role of cross-border power transmission in a renewable-rich power system - a model analysis for Northwestern Europe, J. Environ. Manag. 261 (2020) 110194, https://doi.org/10.1016/j.jenvman.2020.110194.

[38] M. Maeder, O. Weiss, K. Boulouchos, Assessing the need for flexibility technologies in decarbonized power systems: a new model applied to Central Europe, Appl. Energy 282 (2021) 116050, https://doi.org/10.1016/j.apenergy.2020.116050.

[39] A. Stroink, T. Wawer, J.L. Hurink, Cross-border Energy Communities on a Distribution Grid Level, 17th International Conference on the European Energy Market (EEM), 2020, pp. 1-5, https://doi.org/10.1109/EEM49802.2020.9221917.

[40] M. Watcharejyothin, R.M. Shrestha, Effects of cross-border power trade between Laos and Thailand: energy security and environmental implications, Energy Pol. 37 (2009) 1782-1792, https://doi.org/10.1016/j.enpol.2008.12.021. 